\title{
Backward and Forward Compatibility
}

\author{
Jianbiao Pan, California Polytechnic State University, San Luis Obispo \\ Jasbir Bath, Solectron Corporation, Milpitas, California \\ Xiang Zhou, Solectron Corporation, Milpitas, California \\ Dennis Willie, Solectron Corporation, Milpitas, California
}

\section{Introduction}

In response to the European Union (EU) Restriction of Hazardous Substances (RoHS) and other countries' impending lead-free directives, the electronics industry is moving toward lead-free soldering. Total lead-free soldering requires not only lead-free solder paste but also lead-free printed circuit board (PCB) finish and lead-free component/packages. Transitioning tin-lead $(\mathrm{SnPb})$ soldering to totally lead-free soldering is a complex issue and involves movement of the whole electronics industry supply chain. In reality, there is a transition period.

In the early transition phase, consumer electronics manufacturers wanted to convert their products to be lead-free quickly to comply with environmental regulations and avoid a marketing disadvantage. But some lead-free components/packages were not available because components manufacturers were slow in responding to the lead-free transition or there was insufficient demand initially. Thus tin-lead components were assembled with lead-free solder paste. This would be termed a forward compatibility situation.

In the late transition phase, many component manufacturers had migrated to lead-free production. Since the demand for tin-lead components was low, component manufacturers did not want to carry both $\mathrm{SnPb}$ and lead-free production lines due to the cost concerns. Therefore, some components such as memory modules are no longer being made available in $\mathrm{SnPb}$ finish. On the other hand, some products, such as servers, are exempt from the EU RoHS directive until or beyond 2010. Additionally products such as medical equipment, and military and aerospace products are not required to be lead-free. These products want to continue to be built with conventional $\mathrm{SnPb}$ solder paste because the reliability of $\mathrm{SnAgCu}$ - or lead-free - solder 
joints for these high reliability applications is still unknown. This scenario, soldering of lead-free components with $\mathrm{SnPb}$ paste, is known as the backward compatibility situation.

Table 7.1 summarizes the transition to total lead-free soldering. Tin-silvercopper ( $\mathrm{SnAgCu}$ or SAC) solders have been considered to be the best alternative to $\mathrm{SnPb}$ solders for most applications. The most common alloys are $\mathrm{Sn} 3.0 \mathrm{Ag} 0.5 \mathrm{Cu}$ (SAC305) recommended by Japan Electronics and Information Technology Industries Association (JEITA) and IPC Solder Value Council and Sn3.8-3.9Ag0.6-0.7Cu recommended by iNEMI (InterNational Electronics Manufacturing Initiative) and the European consortium - BRITEEURAM. Here $\mathrm{Sn} 3.0 \mathrm{Ag} 0.5 \mathrm{Cu}$ means $3.0 \%$ in weight $\mathrm{Ag}, 0.5 \%$ in weight $\mathrm{Cu}$, with the leading element $\mathrm{Sn}$ making up the balance to $100 \%$ by weight.

Lead-free PCB finishes are used in both the backward compatibility and the forward compatibility assemblies. The most common lead-free PCB finishes include Organic Solderability Preservatives (OSP), Immersion Silver, Electroless Nickel Immersion Gold (ENIG), and Immersion Tin.

Table 1. Transition to Total Lead-free

\begin{tabular}{lll}
\hline & SnPb solder paste & Lead-free solder paste \\
\hline SnPb components & Traditional SnPb soldering & Forward compatibility \\
Lead-free components & Backward compatibility & Total lead-free soldering \\
\hline
\end{tabular}

There are challenges in both forward compatibility and backward compatibility, especially for the BGA (Ball Grid Array)/CSP (Chip Scale Package) component for which this chapter will discuss. The microstructure and reliability data using $\mathrm{SnAgCu}$ BGA/CSP spheres with $\mathrm{SnPb}$ paste will be reviewed. The estimation of mixed solder composition liquidus temperature will be presented. The chapter then presents leadframe and chip components backward compatibility. Forward compatibility will be also briefly discussed. Finally, status of lead-free press-fit connectors will be presented.

\subsection{Challenges to Backward Compatibility}

Backward compatibility means lead-free packages/components attached to a printed circuit board (PCB) using $\mathrm{SnPb}$ solder paste. Since different package types have different metallizations, backward compatibility issues differ by package types. For BGA/CSP packages, the typical package metallization is a $\mathrm{SnAgCu}$ ball. For leadframe components such as Quad Flat Packages (QFPs) and Small Outline Integrated Circuits (SOICs), the typical lead-free component metallization is pure tin $(\mathrm{Sn}), \mathrm{Sn} 3.5 \mathrm{Ag}, \mathrm{Sn} 1.0 \mathrm{Cu}$, 


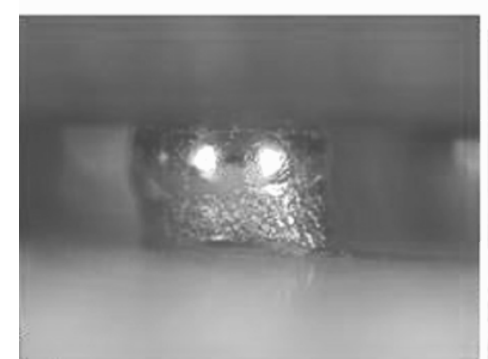

(a)

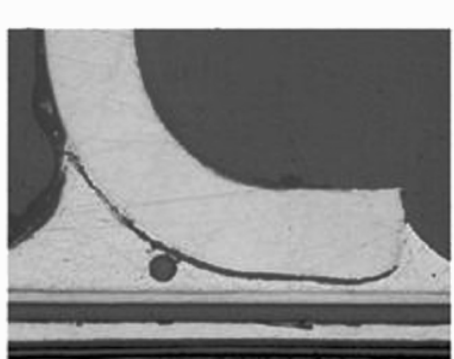

(b)

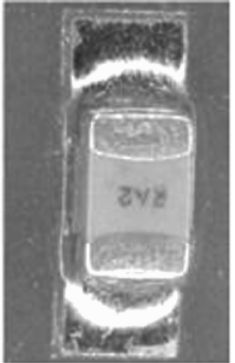

(c)

Fig. 1. Backward Compatibility for Three Package Types (a) SnAgCu BGA sphere with $\mathrm{SnPb}$ paste; (b) Leadfree QFP or SOIC with SnPb paste; (c) Pure Sn chip component with $\mathrm{SnPb}$ paste

$\mathrm{Sn} 2-4 \%$ wt. Bi, NiPdAu or NiAu. For termination or chip components, the most common metallization is pure Sn. Fig. 7.1 shows backward compatibility for these three package types.

A schematic of BGA/CSP backward compatibility is shown in Fig. 7.2. The liquidus temperature of $\mathrm{SnAgCu}$ (SAC305 or SAC387) is between 217 to $221^{\circ} \mathrm{C}$ and the typical reflow peak temperature of $\mathrm{SnAgCu}$ solder paste is between 230 to $250^{\circ} \mathrm{C}$. The liquidus temperature of eutectic $\mathrm{SnPb}$ is $183^{\circ} \mathrm{C}$ and the typical reflow peak temperature of eutectic $\mathrm{SnPb}$ solder paste is between 200 to $220^{\circ} \mathrm{C}$. The question is what reflow profile should be used for backward compatibility assembly, a $\mathrm{SnPb}$ profile, a $\mathrm{SnAgCu}$ profile, or another profile?

If a $\mathrm{SnAgCu}$ profile is used, the $\mathrm{SnAgCu}$ solder ball will melt and the solder ball will self-align as shown in Fig. 7.3(a). But there are two issues. Firstly, the reflow temperature may be too high for other $\mathrm{SnPb}$ components on the same board or the board itself during assembly. Table 7.2 summarizes the component rating per IPC/JEDEC J-STD-020C. Secondly, the flux in $\mathrm{SnPb}$ solder paste may not function properly at such a high reflow

Table 2. Component Rating per IPC/JEDEC J-STD-020C

\begin{tabular}{lll}
\hline & Eutectic SnPb solder & $\mathrm{SnAgCu}$ solder \\
\hline Liquidus temperature & $183^{\circ} \mathrm{C}$ & $217-221^{\circ} \mathrm{C}$ \\
Typical reflow peak & $200 \sim 220^{\circ} \mathrm{C}$ & $230 \sim 250^{\circ} \mathrm{C}$ \\
temp & & \\
Component rating Per & $225+0 /-5^{\circ} \mathrm{C}$ for large thick & $245^{\circ} \mathrm{C}$ for large thick com- \\
IPC/JEDEC J-STD- & components $\left(240^{\circ} \mathrm{C}\right.$ for small ponents $\left(260^{\circ} \mathrm{C}\right.$ for small \& \\
020C & $\&$ thin components $)$ & thin components $)$ \\
\hline
\end{tabular}




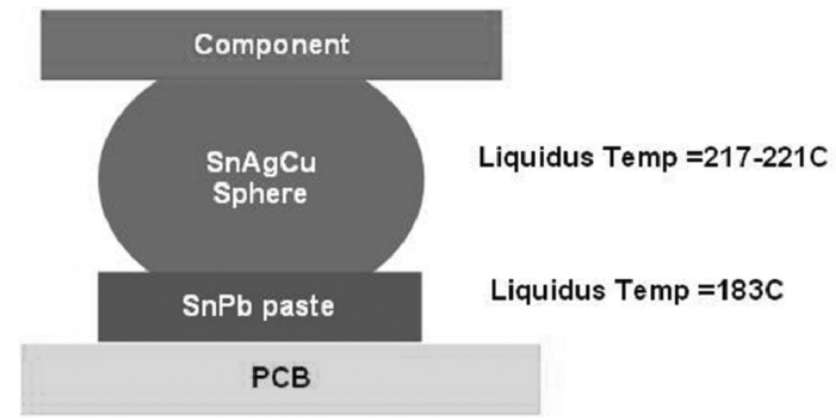

Fig. 2. A Schematic of BGA/CSP Backward Compatibility

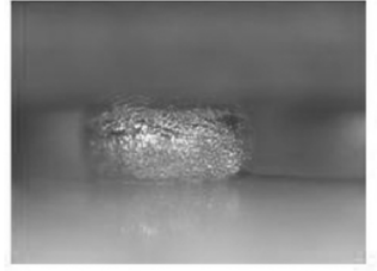

(a)
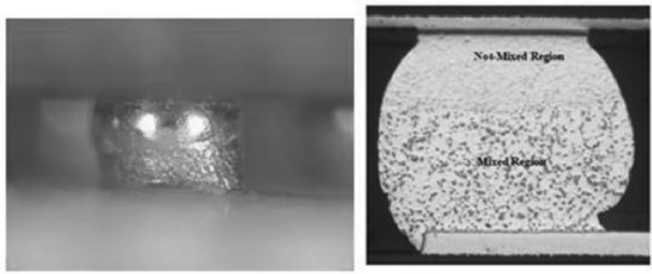

(b)

Fig. 3. Comparison of different reflow profiles in backward compatibility (a) using a $\mathrm{SnAgCu}$ reflow profile; (b) using a $\mathrm{SnPb}$ reflow profile

temperature. On the other hand, if the $\mathrm{SnPb}$ reflow profile is used, the $\mathrm{SnAgCu}$ solder ball will only partially melt and won't be self-aligned as shown in Fig. 7.3 (b). The incomplete mixing of solder and no self-alignment raise reliability concerns. Therefore, the key in BGA/CSP backward compatibility assemblies is to find the minimum reflow peak temperature to be able to achieve complete mixing of $\mathrm{SnPb}$ paste with lead-free components with good self-alignment.

\subsection{Challenges to Forward Compatibility}

Forward compatibility means tin-lead packages/components attached to a PCB using lead-free solder paste. In BGA/CSP forward compatibility shown in Fig. 7.4, a SnAgCu reflow profile is typically used. However, more voids were found in the forward compatibility solder joints [1, 2]. The greater voiding in the solder joints has become a reliability concern [3]. Another issue is that the high $\mathrm{SnAgCu}$ reflow peak temperature may exceed the maximum temperatures that the $\mathrm{SnPb}$ components are allowed to reach. 


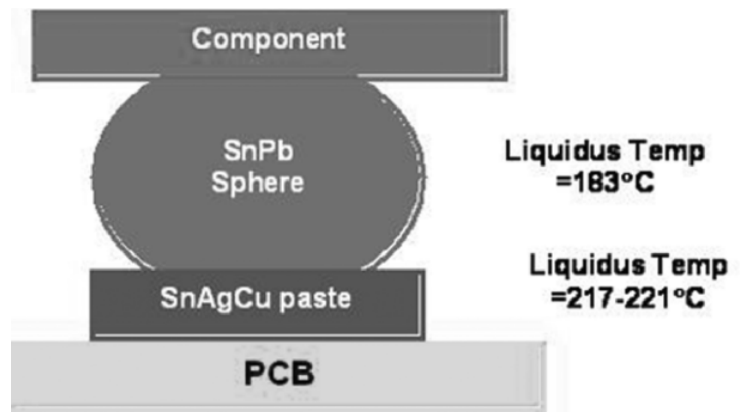

Fig. 4. A Schematic of Forward Compatibility

\section{Reliability of BGA/CSP Backward Compatibility}

\subsection{Microstructure of Backward Compatible Joints}

It is important to evaluate the joint microstructure of lead-free BGAs soldered with $\mathrm{SnPb}$ solder paste since the microstructure is a good indication of the solder joint reliability. The degree of mixing in backward compatibility assembly is expected to be a function of the reflow peak temperature and time above liquidus.

Grossmann et al. investigated various reflow profiles (peak temperature and time above liquidus) on the microstructure of the solder joint [4]. The package they tested was a PBGA200 with $13 \mathrm{~mm} \times 13 \mathrm{~mm}$ component body size, $1 \mathrm{~mm}$ thick, $0.8 \mathrm{~mm}$ pitch, and $7 \mathrm{~mm} \times 7 \mathrm{~mm}$ die size. The solder ball in the PBGA was Sn3.8Ag0.7Cu with a diameter of $0.5 \mathrm{~mm}$ and a height of $0.3 \mathrm{~mm}$. The PCBs were made of glass epoxy FR-4 with a thickness of $1.58 \mathrm{~mm}$ (62 mil). The PCB finish was electroless Ni immersion Au (ENIG). The stencil used for solder paste printing was laser cut with aperture openings of $0.7 \mathrm{~mm}$ (28 mil) $(1: 1$ to the pad size) and a thickness of $0.15 \mathrm{~mm}$ (6 mil). The solder paste was $\mathrm{Sn} 36 \mathrm{~Pb} 2 \mathrm{Ag}$, Type 3 with rosin-based no-clean flux. Table 7.3 summarizes the results of the work. Their results show that the $\mathrm{SnPbAg}$ solder paste interacted with $\mathrm{SnAgCu}$ ball even at a peak temperature of $210^{\circ} \mathrm{C}$, but the solder ball was only partially mixed with the solder paste. The $\mathrm{SnAgCu}$ ball was fully dissolved when the peak temperature reached $217^{\circ} \mathrm{C}$. The dendrites got smaller as the peak temperature increases. It should be noted that the melting point of $\mathrm{Sn} 36 \mathrm{~Pb} 2 \mathrm{Ag}$ is $179^{\circ} \mathrm{C}$ compared with $183^{\circ} \mathrm{C}$ for the more common $\mathrm{Sn} 37 \mathrm{~Pb}$ solder. 
Table 3. Summary of Grossmann et al. [4]'s Results

\begin{tabular}{lccl}
\hline $\begin{array}{l}\text { Peak tem- } \\
\text { perature } \\
\left({ }^{\circ} \mathrm{C}\right)\end{array}$ & $\begin{array}{l}\text { Time above } \\
\text { SnAgCu liq- } \\
\text { uidus (sec.) }\end{array}$ & $\begin{array}{l}\text { Time above } \\
\text { SAC387 liq- } \\
\text { uidus (sec.) }\end{array}$ & Results \\
\hline 210 & 62 & - & $\begin{array}{l}\text { SAC ball partially reacted with } \\
\text { SnPbAg solder }\end{array}$ \\
217 & 66 & - & $\begin{array}{l}\text { SAC ball is fully molten, but the dis- } \\
\text { pension of Pb is inhomogeneous, IMC } \\
\text { is formed }\end{array}$ \\
218 & 82 & 6 & $\begin{array}{l}\text { Completely mixed; the dendrites are } \\
\text { smaller than that soldered at 217C } \\
223\end{array}$ \\
227 & 71 & 28 & $\begin{array}{l}\text { Completely mixed; homogeneous dis- } \\
\text { tribution of the Pb-rich phase; fine } \\
\text { IMC. }\end{array}$ \\
\hline
\end{tabular}

Bath et al. used a FBGA676 I/O, with a pitch of $1.0 \mathrm{~mm}$ on their backward compatibility study [5]. The package body was $27 \mathrm{~mm} \times 27 \mathrm{~mm}$ in body size containing a die of $17 \mathrm{~mm} \times 17 \mathrm{~mm}$ in size. The solder ball diameter was $0.6 \mathrm{~mm}$. The solder ball composition was $\mathrm{Sn} 4.0 \mathrm{Ag} 0.5 \mathrm{Cu}$. The package surface finish was $\mathrm{Ni} / \mathrm{Au}$. The printed circuit board was made of FR-4 with a thickness of $2.34 \mathrm{~mm}(92 \mathrm{mil})$ and a size of $220 \mathrm{~mm} \times 140$ $\mathrm{mm}$. The board finish was OSP. The stencil used was $0.127 \mathrm{~mm}(5 \mathrm{mil})$ thick with openings of $0.457 \mathrm{~mm}(18 \mathrm{mil})$ diameter. Two reflow profiles were used. One was $205^{\circ} \mathrm{C}$ peak temperature and 67 seconds over $183^{\circ} \mathrm{C}$, and the other was $214^{\circ} \mathrm{C}$ peak temperature and 77 seconds over $183^{\circ} \mathrm{C}$. The microstructures of the solder joints are shown in Fig. 7.5. It is clearly shown that $\mathrm{Pb}$ was partially diffused into the $\mathrm{SnAgCu}$ ball when the reflow peak temperature was at $205^{\circ} \mathrm{C}$. A nearly full mixing was achieved when the reflow peak temperature was at $214^{\circ} \mathrm{C}$, but the dispersion of $\mathrm{Pb}$ was not uniform.

Zbrzezny et al. investigated various reflow profiles and concluded that complete mixing of the solders was achieved when the reflow peak temperature reached $218-222^{\circ} \mathrm{C}[6]$.

Most of these studies believed that full mixing was achieved only when the reflow peak temperature exceeded $217^{\circ} \mathrm{C}[4,6,7]$, however, a full mixing of the $\mathrm{SnPb}$ paste with the $\mathrm{SnAgCu}$ ball can be achieved when the peak reflow temperature is below $217^{\circ} \mathrm{C}$. For example, Nandagopal et al. observed that a full mixing of the $\mathrm{SnPb}$ paste and the $\mathrm{SnAgCu}$ ball was accomplished at a peak reflow temperature of $210^{\circ} \mathrm{C}$ for about 15 to 25 seconds $[8,9]$. They used the Differential Scanning Calorimeter (DSC) to characterize the time required to achieve full mixing. Handwerker indicated that full mixing of the tin-lead paste and lead-free $\mathrm{Sn} 3.9 \mathrm{Ag} 0.6 \mathrm{Cu}$ solder ball 


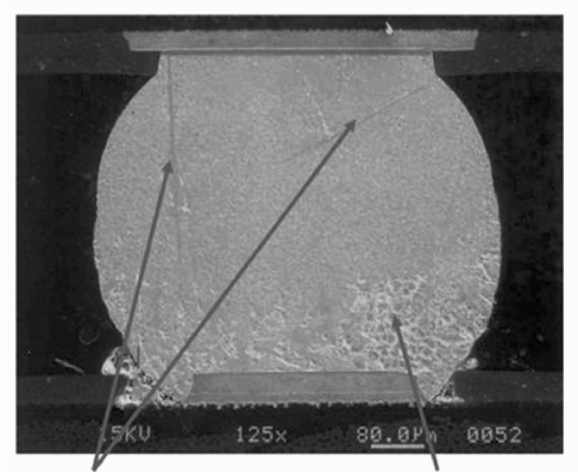

$\mathrm{Ag}_{3} \mathrm{Sn} \mathrm{IMC}$

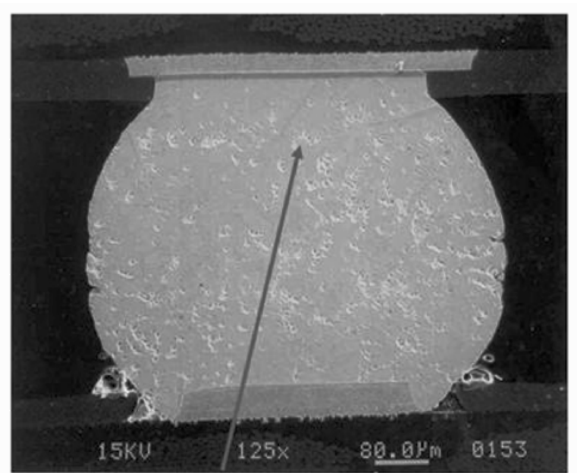

$\mathrm{Pb}$ phase

(a)

(b)

Fig. 5. SEM pictures of reflowed at a) $205^{\circ} \mathrm{C}$ peak temperature and 67 seconds over $183^{\circ} \mathrm{C}$; b) $214^{\circ} \mathrm{C}$ peak temperature and 77 seconds over $183^{\circ} \mathrm{C}$

occurred at $207^{\circ} \mathrm{C}$ with a sufficient time, the $\mathrm{Sn3} .9 \mathrm{Ag} 0.6 \mathrm{Cu}$ solder ball constituting $75 \%$ of the final solder [10]. Snugovsky et al. described the mixing process using a $\mathrm{SnPb}$ phase diagram [11]. From the study, they concluded that a complete mixture may be achieved at a temperature lower than $217^{\circ} \mathrm{C}$ and that the temperature depends on solder ball composition, ball/solder paste ratio, dwell time, and component size.

\subsection{Reliability of BGA/CSP Backward Compatibility}

A significant number of experimental studies have been done recently on investigating the solder joint reliability of BGA/CSP backward compatibility using various reflow profiles $[5,6,7,8,9,11,12,13,14,15,16]$.

\section{Poor Reliability when the BGA/CSP Ball is Partially Mixed}

It is evident that the reliability of solder joint interconnections in backward compatibility assemblies degrades significantly if $\mathrm{SnAgCu}$ solder spheres are only partly melted in backward compatibility. Hillman et al. evaluated the reliability of a BGA package assembled using a peak reflow temperature of $215^{\circ} \mathrm{C}$ with the duration time above $200^{\circ} \mathrm{C}$ at 40 seconds [12]. They observed partial mixing of $\mathrm{Pb}$ in the joint microstructure. The reliability of the solder joint was very poor as the solder joint failed at only 137 cycles in temperature cycling from $-55^{\circ} \mathrm{C}$ to $+125^{\circ} \mathrm{C}$ with dwell times of $11 \mathrm{~min}$ utes at each extreme and a ramp rate of $10^{\circ} \mathrm{C} /$ minute maximum per IPC9701 guidelines. They used BGA/CSP components with $\mathrm{Sn} 4.0 \mathrm{Ag} 0.5 \mathrm{Cu}$ 
solder alloy. The reflow profile was developed using thermocouples attached to the outside edge of the BGA solder spheres with conductive epoxy. The test vehicle was FR4, $2.08 \mathrm{~mm}$ (82 mil) thick, and a glass transition temperature of $170^{\circ} \mathrm{C}$ minimum. The size of the board was $203 \mathrm{~mm} \times 279 \mathrm{~mm}$ ( 8 inch $\times 11$ inch) and the board finish was ENIG with 18 layers of $1 / 2$ ounce $\mathrm{Cu}$. The component under test was $256 \mathrm{I} / \mathrm{O}$ daisy chained, $17 \mathrm{~mm} \times 17 \mathrm{~mm}$, $1.0 \mathrm{~mm}$ pitch, full array, $\mathrm{Sn} 4 \mathrm{Ag} 0.5 \mathrm{Cu}$ solder ball alloy. The stencil used was $0.127 \mathrm{~mm}$ (5 mil) thick, with 1:1 board pad to stencil aperture match and $0.381 \mathrm{~mm}$ (15 mil) diameter round apertures. Though solder paste volume was not measured, $95 \%$ paste transfer ratio was assumed.

Gregorich \& Holmes reported that the reliability of backward compatibility assemblies when the mixed assembly was reflowed at the peak temperature of $200^{\circ} \mathrm{C}$ and the duration of time above $183^{\circ} \mathrm{C}$ at 62 seconds was much poorer than that of the control $\mathrm{SnAgCu}$ ball with $\mathrm{SnAgCu}$ paste in both the accelerated temperature cycling test from $-40^{\circ} \mathrm{C}$ to $+125^{\circ} \mathrm{C}$ and the mechanical shock test [13]. The poor reliability was believed to be due to the inhomogeneous microstructure resulting from partial mixing of $\mathrm{Pb}$. The reliability of backward compatibility assembly improved as the reflow temperature increased to $225^{\circ} \mathrm{C}$. The package investigated was a CSP with $0.5 \mathrm{~mm}$ pitch. These components were $14 \mathrm{~mm} \times 14 \mathrm{~mm} \times 1.2 \mathrm{~mm}$ in size. The solder spheres in the component were $\mathrm{Sn} 4.0 \mathrm{Ag} 0.5 \mathrm{Cu}$. The PCB was 4-layer, $0.8 \mathrm{~mm}$ thick FR-4 board, $100 \mathrm{~mm} \times 40 \mathrm{~mm}$ in size, with $\mathrm{Ni} / \mathrm{Au}$ board surface finish. The stencil used in the study was $0.127 \mathrm{~mm}(5 \mathrm{mil})$ thick and 1:1 ratio between package land and board land.

Hua et al. reported similar results showing that incomplete mixing leads to unacceptable solder joints $[7,14]$. Therefore, it is critical to achieve complete mixing of $\mathrm{SnPb}$ paste with $\mathrm{SnAgCu}$ ball in BGA/CSP backward compatibility assembly.

\section{Reliability Comparison between Backward Compatibility versus SnPb Control and SnAgCu Control Assemblies}

If complete mixing is achieved in backward compatibility assemblies, is the reliability better, equivalent or worse than that of $\mathrm{SnPb}$ control and $\mathrm{SnAgCu}$ control assemblies? There are conflicting reports about whether the reliability of backward compatibility assembly is better or poorer than that of $\mathrm{SnAgCu}$ balls assembled with $\mathrm{SnAgCu}$ solder paste. In general it is equivalent or worse. Bath et al. found that the reliability of backward compatibility assembly in accelerated temperature cycling (ATC) from $0^{\circ} \mathrm{C}$ to $100^{\circ} \mathrm{C}$ with 40 minute a cycle, even when the full mixing was achieved, was poorer than that of both $\mathrm{SnAgCu}$ ball/ $\mathrm{SnAgCu}$ paste and $\mathrm{SnPb}$ ball/ $\mathrm{SnPb}$ paste as shown in Fig. 7.6 [5]. It should be pointed out that there is 
no statistically significant difference in reliability between the reflow peak temperature of $205^{\circ} \mathrm{C}$ and $215^{\circ} \mathrm{C}$. But Bandagopal et al. found that the reliability of backward compatibility assembly in both ATC from $0^{\circ} \mathrm{C}$ to $100^{\circ} \mathrm{C}$ and $-40^{\circ} \mathrm{C}$ to $125^{\circ} \mathrm{C}$ was better than the $\mathrm{SnPb}$ assembly when full mixing was achieved [8]. Bandagopal et al. also found that the reliability of backward compatibility assemblies surpassed the reliability of $\mathrm{SnAgCu}$ control assemblies in ATC from $-40^{\circ} \mathrm{C}$ to $125^{\circ} \mathrm{C}$, but not in ATC from $0^{\circ} \mathrm{C}$ to $100^{\circ} \mathrm{C}$.

Although a considerable amount of work has been done so far on the backward compatibility assembly and its reliability, the minimum temperature able to achieve full mixing is still unknown. The key in backward compatibility assembly is to develop a reflow profile with the peak temperature high enough to be able to achieve full mixing of the $\mathrm{SnPb}$ paste and the $\mathrm{SnAgCu}$ ball, but low enough (prefer below $220^{\circ} \mathrm{C}$ ) so that $\mathrm{SnPb}$ components and the board won't be damaged. Therefore, it is critical to know the minimum reflow peak temperature that is capable of achieving a complete mixing of $\mathrm{SnPb}$ paste with lead-free components.

Work in the iNEMI backward compatibility group is helping to define and understand the peak temperature and time above liquidus to use for certain types of lead-free CSP/BGA components with tin-lead paste which

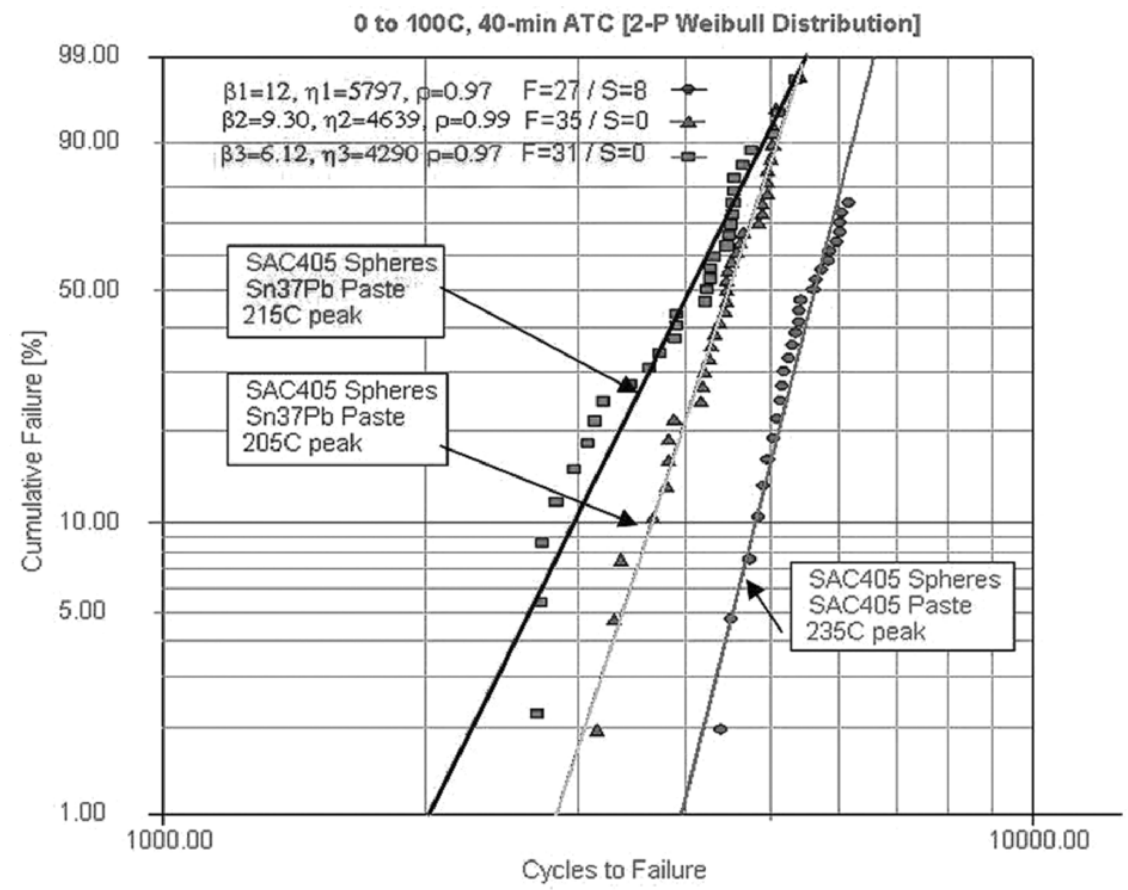

Fig. 6. Backward reliability data [5] 
will be put into ATC reliability testing [17]. Components to be ATC reliability tested in iNEMI project will be the SBGA600 package with a pitch of $1.27 \mathrm{~mm}$ and a size of $45 \mathrm{~mm} \times 45 \mathrm{~mm}$, the PBGA324 package with a pitch of $1 \mathrm{~mm}$ and a size of $23 \mathrm{~mm} \times 23 \mathrm{~mm}$, the CABGA288 package with a pitch of $0.8 \mathrm{~mm}$ and a size of $19 \mathrm{~mm} \times 19 \mathrm{~mm}$, and the CTBGA132 package with a pitch of $0.5 \mathrm{~mm}$ and a size of $8 \mathrm{~mm} \times 8 \mathrm{~mm}$.

\section{Estimation of Mixed Composition Liquidus Temperature}

\subsection{Mixed Composition Calculation}

There are four alloying elements in the mixed composition when $\mathrm{SnAgCu}$ $\mathrm{BGA} / \mathrm{CSP}$ components are soldered with $\mathrm{SnPb}$ paste: $\mathrm{Sn}, \mathrm{Ag}, \mathrm{Cu}$, and $\mathrm{Pb}$. The percentage of each metal element in the mixed composition can be calculated $[18,19]$

$$
\begin{gathered}
W_{P b}=\frac{f_{P b} \times V_{\text {Paste }} \times f_{m} \times d_{\text {SnPb }}}{V_{\text {Paste }} \times f_{m} \times d_{\text {SnPb }}+V_{\text {Ball }} \times d_{\text {SnAgCu}}} \\
W_{A g}=\frac{f_{A g} \times V_{\text {Ball }} \times d_{\text {SnAgCu }}}{V_{\text {Paste }} \times f_{m} \times d_{\text {SnPb }}+V_{\text {Ball }} \times d_{\text {SnAgCu}}} \\
W_{C u}=\frac{f_{C u} \times V_{\text {Ball }} \times d_{\text {SnAgCu }}}{V_{\text {Paste }} \times f_{m} \times d_{\text {SnPb }}+V_{\text {Ball }} \times d_{\text {SnAgCu}}} \\
W_{\text {Sn }}=100-\mathrm{W}_{\mathrm{Pb}}-\mathrm{W}_{\mathrm{Ag}}-\mathrm{W}_{\mathrm{Cu}}
\end{gathered}
$$

where $W_{P b}, W_{A g}, W_{C u}$, and $W_{S n}$ are the weight percentages of $\mathrm{Pb}, \mathrm{Ag}, \mathrm{Cu}$, and $\mathrm{Sn}$ in the mixed compositions, respectively; $f_{P b}$ is the percentage of $\mathrm{Pb}$ by weight in $\mathrm{SnPb}$ solder paste; $f_{A g}$ and $f_{C u}$ are the weight percentage of $\mathrm{Ag}$ and $\mathrm{Cu}$ in $\mathrm{SnAgCu}$ alloy; $f_{m}$ is the volume percentage of metal content in $\mathrm{SnPb}$ solder paste; $d_{S n P b}$ and $d_{S n A g C u}$ are the density of $\mathrm{SnPb}$ and $\mathrm{SnAgCu}$ alloys. $V_{\text {paste }}$ is the $\mathrm{SnPb}$ solder paste volume, which can be calculated

$$
V_{\text {paste }}= \begin{cases}L^{2} H(T R) & \text { for square aperature } \\ \pi\left(\frac{D}{2}\right)^{2} H(T R) & \text { for round aperture }\end{cases}
$$


where $\mathrm{L}$ is stencil aperture length for square aperture, $\mathrm{H}$ is stencil thickness, $\mathrm{D}$ is stencil aperture diameter for round aperture, and TR is the paste transfer ratio, which is defined as the ratio of the volume of solder paste deposited to the volume of the aperture.

$V_{\text {ball }}$ is the volume of a solder ball in the BGA/CSP component. If the ball diameter, $\mathrm{D}$, is given, the ball volume can be calculated

$$
V_{\text {ball }}=\frac{4}{3} \pi\left(\frac{D}{2}\right)^{3}
$$

If the sphere is reflowed and the ball height, $\mathrm{H}$, and radius, $\mathrm{R}$, are given, the ball volume can be calculated

$$
V_{\text {ball }}=\frac{2}{3} \pi R^{3}-\pi R^{3}\left[\frac{1}{3}\left(\frac{H-R}{R}\right)^{3}-\left(\frac{H-R}{R}\right)\right]
$$

For eutectic $\mathrm{SnPb}$ solder paste, $f_{P b}$ is 37 and typical value of $f_{m}$ is 0.5 (or $50 \%$ ). For $\mathrm{Sn} 3.0 \mathrm{Ag} 0.5 \mathrm{Cu}$ solder alloy, $f_{A g}=3.0$ and $f_{C u}=0.5$. The density of eutectic $\operatorname{Sn} 37 \mathrm{~Pb}, d_{S n P b}$, is $8.4 \mathrm{~g} / \mathrm{cm}^{3}$ and the density of $\mathrm{Sn} 4.0 \mathrm{Ag} 0.5 \mathrm{Cu}$, $d_{\text {SnAgCu}}$, is $7.394 \mathrm{~g} / \mathrm{cm}^{3}$ [20].

Use the Bath et al. study [5] as an example. A $1 \mathrm{~mm}$ pitch BGA (FG676) package used with a $0.61 \mathrm{~mm}(24 \mathrm{mil}) \mathrm{Sn} 3.0 \mathrm{Ag} 0.5 \mathrm{Cu}$ ball diameter was assembled with $\mathrm{Sn} 37 \mathrm{~Pb}$ paste. The solder paste was printed using a 0.127 $\mathrm{mm}(5 \mathrm{mil})$ thick stencil with a $0.457 \mathrm{~mm}(18 \mathrm{mil})$ diameter round stencil aperture. The $\mathrm{SnPb}$ paste had 50\% metal content in volume. Assuming a $90 \%$ solder paste transfer ratio, using Eq. 7.6, we can calculate that the volume of the $\mathrm{Sn} 3 \mathrm{Ag} 0.5 \mathrm{Cu}$ ball is $0.118 \mathrm{~mm}^{3}\left(7235 \mathrm{mil}^{3}\right)$. Using Eq. 7.5, we can calculate the volume of $\mathrm{SnPb}$ paste as $0.0188 \mathrm{~mm}^{3}\left(1125 \mathrm{mil}^{3}\right)$. Using Eqs. 7.1 to 7.4, we can get the final mixed alloy composition:

$$
\begin{gathered}
W_{P b}=\frac{37 \times 0.0188 \times 0.5 \times 8.4}{0.0188 \times 0.5 \times 8.4+0.118 \times 7.394}=3.07 \\
W_{A g}=\frac{3.0 \times 0.118 \times 7.394}{0.0188 \times 0.5 \times 8.4+0.118 \times 7.394}=2.75 \\
W_{C u}=\frac{0.5 \times 0.118 \times 7.394}{0.0188 \times 0.5 \times 8.4+0.118 \times 7.394}=0.46 \\
W_{S n}=100-3.07-2.75-0.46=93.7
\end{gathered}
$$

Therefore, the mixed alloy joint composition is $93.7 \% \mathrm{Sn}, 3.1 \% \mathrm{~Pb}$, $2.8 \% \mathrm{Ag}$, and $0.5 \% \mathrm{Cu}$, all in weight. 


\subsection{Estimation of Mixed Composition Liquidus Temperature}

After we know the mixed compositions, the next question becomes what in this case is the liquidus temperature of the mixed composition Sn3.$1 \mathrm{~Pb} 2.8 \mathrm{Ag} 0.5 \mathrm{Cu}$. The phase diagram of common binary and ternary systems that are relevant to solders is available at the Fundamental Properties of $\mathrm{Pb}$-Free Solder Alloys Chapter in this book. But the phase diagram of the complex quaternary $\mathrm{SnPbAgCu}$ is currently not available. The phase equilibria can be calculated from thermodynamic databases using the CALPHAD method [21]. Thermodynamic calculation is a very useful tool in obtaining phase diagram information, but it requires reliable thermodynamic databases and specialized knowledge.

Kattner and Handwerker stated that the liquidus temperature of ternary and quaternary systems could be calculated using the simple linearization of the binary liquidus lines [22]

$$
\begin{aligned}
T_{l}= & 232^{\circ} \mathrm{C}-3.1 W_{A g}-1.6 W_{B i}-7.9 W_{C u}-3.5 W_{G a} \\
& -1.9 W_{I n}-1.3 W_{P b}+2.7 W_{S b}-5.5 W_{Z n}
\end{aligned}
$$

limits: $W_{A g}<3.5 ; W_{B i}<43 ; W_{C u}<0.7 ; W_{G a}<20 ; W_{I n}<25 ; W_{P b}<38$; $38 ; W_{S b}<6 ; W_{Z n}<6$

where $T_{l}$ is the liquidus temperature of Sn-rich solder alloys, $232 \mathrm{C}$ is the liquidus temperature of $\mathrm{Sn}, W_{A g}, W_{B i}, W_{C u}, W_{G a}, W_{I n}, W_{P b}, W_{S b}, W_{Z n}$ is the percentage in weight of $\mathrm{Ag}, \mathrm{Bi}, \mathrm{Cu}, \mathrm{Ga}, \mathrm{In}, \mathrm{Pb}, \mathrm{Sb}$, and $\mathrm{Zn}$, respectively. The coefficient before these alloying elements is the slope of the binary liquidus lines. For example, 7.9 is the slope of $\mathrm{SnCu}$ binary liquidus lines when $\mathrm{Cu}$ is less than $0.7 \%$ in weight; 1.3 is the slope of $\mathrm{SnPb}$ binary liquidus lines when $\mathrm{Pb}$ is less than $38 \%$ in weight; and so on. It should be emphasized that the limitation of the simple linearization is $W_{A g}<3.5$; $W_{B i}<43 ; W_{C u}<0.7 ; W_{G a}<20 ; W_{I n}<25 ; W_{P b}<38 ; W_{S b}<6 ; W_{Z n}<6$. It should also be noted that Eq. 7.8 is an approximation.

Based on Eq. 7.8, the liquidus temperature of the quaternary $\mathrm{SnPbAgCu}$ system, a typical alloy system in both forward compatibility assembly and backward compatibility assembly, can be calculated

$$
T_{l}=232^{\circ} \mathrm{C}-3.1 W_{A g}-7.9 W_{C u}-1.3 W_{P b}
$$

with limits: $\mathrm{W}_{\mathrm{Ag}}<3.5 ; \mathrm{W}_{\mathrm{Cu}}<0.7 ; \mathrm{W}_{\mathrm{Pb}}<38$;

Based on Eq. 7.9, the liquidus temperature of $\mathrm{Sn} 3.0 \mathrm{Ag} 0.5 \mathrm{Cu}$ is,

$$
T_{l}=232^{\circ} \mathrm{C}-3.1 \times 3.0-7.9 \times 0.5-1.3 \times 0=219^{\circ} \mathrm{C}
$$


If $\mathrm{Ag}$ content is over $3.5 \%$ and less than $4 \% \mathrm{wt}, \mathrm{Ag}_{3} \mathrm{Sn}$ is primary phase. In this case, Eq. 7.9 is not valid. A simple fix is to add $5^{\circ} \mathrm{C}$ to Eq. 7.8. Thus, the liquidus temperature of $\mathrm{Sn} 3.8 \mathrm{Ag} 0.7 \mathrm{Cu}$ is

$$
T_{l}=232^{\circ} \mathrm{C}-3.1 \times 3.8-7.9 \times 0.7-1.3 \times 0+5=220^{\circ} \mathrm{C}
$$

Currently the reflow profiles in backward compatibility assembly are developed through costly trial-and-error methods. It is expected that the estimation of the mixed composition liquidus temperatures will be able to guide process engineers to develop the right reflow profile in backward compatibility assembly.

Table 7.4 summarizes the final joint compositions and liquidus temperature with $\mathrm{SnAgCu}$ ball and $\mathrm{Sn} 37 \mathrm{~Pb}$ paste for typical BGA/CSP component pitch levels. The aperture size, shape, stencil thickness and ball diameter are based on typical guidelines for no-clean paste. The transfer ratio is assumed based on experience. It shows that the final liquidus temperature is lower than $217^{\circ} \mathrm{C}$, the liquidus temperature of $\mathrm{SnAgCu}$. The liquidus temperature can be as low as $201^{\circ} \mathrm{C}$. As the component pitch decreases (except for the case of $0.5 \mathrm{~mm}$ pitch), the weight percentage of $\mathrm{Pb}$ increases and the liquidus temperature decreases. Eqs. 7.1 to 7.4 imply that the liquidus temperature depends on the ratio of BGA ball volume and solder paste volume.

Table 4. Final Joint Compositions and Liquidus Temperature with $\mathrm{SnAgCu}$ Ball and $\mathrm{Sn} 37 \mathrm{~Pb}$ Paste

\begin{tabular}{|c|c|c|c|c|c|}
\hline Pitch (mm) & 1.27 & 1.0 & 0.8 & 0.65 & 0.5 \\
\hline Aperture size in $\mathrm{mm}$ & 0.533 & 0.457 & 0.406 & 0.356 & 0.279 \\
\hline (mil) & $(21)$ & $(18)$ & $(16)$ & $(14)$ & $(11)$ \\
\hline Aperture shape & Round & Square & Square & Square & Square \\
\hline Stencil thickness in $\mathrm{mm}$ & 0.152 & 0.127 & 0.127 & 0.127 & 0.102 \\
\hline$(\mathrm{mil})$ & $(6)$ & $(5)$ & $(5)$ & $(5)$ & (4) \\
\hline Solder paste transfer ratio $(\%)$ & 100 & 90 & 85 & 80 & 90 \\
\hline Ball diameter in $\mathrm{mm}$ & 0.711 & 0.559 & 0.356 & 0.254 & 0.254 \\
\hline$(\mathrm{mil})$ & $(28)$ & $(22)$ & $(14)$ & $(10)$ & $(10)$ \\
\hline Weight $\%$ of $\mathrm{Pb}$ & 3.4 & 4.8 & 11.1 & 17.0 & 11.9 \\
\hline Weight $\%$ of $\mathrm{Ag}$ & 2.7 & 2.6 & 2.1 & 1.6 & 2.1 \\
\hline SAC305 Weight $\%$ of $\mathrm{Cu}$ & 0.5 & 0.4 & 0.3 & 0.3 & 0.3 \\
\hline $\begin{array}{ll}\text { Ball } & \begin{array}{l}\text { Estimated liquidus } \\
\text { temperature }\left({ }^{\circ} \mathrm{C}\right)\end{array}\end{array}$ & 216 & 214 & 208 & 203 & 208 \\
\hline Weight $\%$ of $\mathrm{Ag}$ & 3.6 & 3.5 & 2.8 & 2.2 & 2.7 \\
\hline SAC405 Weight $\%$ of $\mathrm{Cu}$ & 0.5 & 0.4 & 0.3 & 0.3 & 0.3 \\
\hline $\begin{array}{ll}\text { Ball } & \begin{array}{l}\text { Estimated liquidus } \\
\text { temperature }\left({ }^{\circ} \mathrm{C}\right)\end{array}\end{array}$ & 218 & 217 & 206 & 201 & 205 \\
\hline
\end{tabular}




\subsection{Effect of Pb Content on Backward Compatibility Reliability}

Eq. 7.9 shows that a higher $\mathrm{Pb}$ percentage in the mixed composition can reduce the mixed composition liquidus temperature. The higher $\mathrm{Pb}$ percentage can be achieved by printing more $\mathrm{SnPb}$ solder paste or reducing the $\mathrm{SnAgCu}$ solder ball volume. But increasing the lead content in the solder joint can also lead to more issues as lead tends to segregate at the tin grain boundaries which can be a source of crack initiation or propagation. $\mathrm{Zhu}$ et al. studied the effect of $\mathrm{Pb}$ contamination on the lead-free solder joint microstructure and observed a $\mathrm{Pb}$-rich phase formed in the bulk solder when the lead-free solder contains $\mathrm{Pb}$ impurity [23]. Zeng discussed the influence of the $\mathrm{Pb}$-rich phase on solder joint reliability [24]. The $\mathrm{Pb}$-rich phase may be the weakest region in the bulk solder, and the crack may propagate along the $\mathrm{Pb}$-rich phase interface during reliability testing.

However, some experimental results did not follow the explanation. Bandagopal et al. found that the reliability of backward compatibility assembly in both ATC from $0^{\circ} \mathrm{C}$ to $100^{\circ} \mathrm{C}$ and $-40^{\circ} \mathrm{C}$ to $125^{\circ} \mathrm{C}$ was better than the $\mathrm{SnPb}$ assembly when full mixing was achieved [9]. Furthermore, the reliability data of $\mathrm{SnPb} \mathrm{BGA}$ ball soldered with $\mathrm{SnAgCu}$ paste (or forward compatibility), where higher $\mathrm{Pb}$ content existed in the mixed compositions, was better or equal to that of $\mathrm{SnPb}$ ball/ $\mathrm{SnPb}$ paste control assemblies [25]. Hunt and Wickham concluded that there should be few solder joint reliability problems when mixing $\mathrm{SnPb}$ and lead-free components and solder alloys (with lead contamination in the range of 1 to $10 \%$ ) [26]. Therefore, it is difficult to draw a conclusion regarding the effect of $\mathrm{Pb}$ content on backward compatibility reliability although there is evidence to show that it could be detrimental [12]. For the case where the lead-free $\mathrm{SnAgCu}$ paste is assembled with $\mathrm{SnPb} \mathrm{BGA} / \mathrm{CSP}$ components, if the voiding is excessive, this may lead to reliability issues from excess voiding which reduce the effective solder cross-sectional area or if the ball size and pitch is small, bridging may occur between adjacent spheres.

\subsection{Comparison of Estimated Liquidus Temperature and the Experimental Results}

To assess the method to calculate estimated liquidus temperatures, calculated liquidus temperatures were compared with published experimental results. The estimated temperatures and the published experimental results are summarized in Table 7.5. If the reflow peak temperature used was higher than the estimated liquidus temperature, full mixing was expected. 
Table 5. Comparison of the Estimated Liquidus Temperature and the Reported Experimental Results

\begin{tabular}{llll}
\hline Reference & $\begin{array}{l}\text { Estimated liquidus } \\
\text { temperature }\end{array}$ & $\begin{array}{l}\text { Peak reflow tem- } \\
\text { perature used }\end{array}$ & Experimental results \\
\hline Gregorich \& & $209^{\circ} \mathrm{C}$ & $200^{\circ} \mathrm{C}$ & Partial mixing \\
Holmes [13] & & $225^{\circ} \mathrm{C}$ & Full mixing \\
Hillman et al. [12] & $219^{\circ} \mathrm{C}$ & $215^{\circ} \mathrm{C}$ & Partial mixing \\
Grossmann et al. [4] & $216^{\circ} \mathrm{C}$ & $210^{\circ} \mathrm{C}$ & Partial mixing \\
& & $217^{\circ} \mathrm{C}$ & Full mixing \\
Nandagopal et al. & $212^{\circ} \mathrm{C}$ & $210^{\circ} \mathrm{C}$ & Full mixing \\
[9] & & $227^{\circ} \mathrm{C}$ & Full mixing \\
Bath et al. [5] & $218^{\circ} \mathrm{C}$ & $205^{\circ} \mathrm{C}$ & Partial mixing \\
& & $214^{\circ} \mathrm{C}$ & Full mixing \\
\hline
\end{tabular}

Otherwise, partial mixing was expected. Overall, Table 7.5 shows that the estimated liquidus temperatures are generally consistent with reported experimental results. There are small variances between the estimated temperature and the reported results of studies in Nandagopal et al. [9] and Bath et al. [5]. This could be due to the inaccuracy of paste transfer ratio assumptions and the fact that a sufficient time over liquidus $\left(183^{\circ} \mathrm{C}\right)$ for the tin-lead solder paste could also affect the result. Since only a few studies have reflow peak temperatures close to the estimated liquidus temperature, further experimental study is needed to validate the accuracy of the estimation method.

\section{Chip Component and Lead-Frame Component Backward Compatibility}

\subsection{Calculation of Mixture Composition Liquidus Temperature for Chip Terminations}

The typical surface finish for $\mathrm{SnPb}$ chip terminations is $90 \mathrm{Sn} 10 \mathrm{~Pb}$ with a liquidus temperature of $219^{\circ} \mathrm{C}$. The typical surface finish for lead-free chip terminations is $100 \% \mathrm{Sn}$ with a liquidus temperature of $232^{\circ} \mathrm{C}$. Using the 0603 chip as an example, given chip component dimensions [27, 28] and a final plating of $100 \% \mathrm{Sn}$ (lead-free) or $90 \% \mathrm{Sn} 10 \% \mathrm{~Pb}(\mathrm{SnPb})$ of 7.5 to 15 micron thickness, the solder volume in the chip component can be calculated. Knowing the component size and typical stencil apertures, the $\mathrm{SnPb}$ solder paste volume deposited can be calculated.

Table 7.6 summarizes the calculated minimum and maximum liquidus temperature of mixed compositions with $\mathrm{Sn} 37 \mathrm{~Pb}$ paste based on the minimum 
Table 6. Calculated Final Liquidus Temperature of Chip Component Solder Joint

\begin{tabular}{lllllll}
\hline $\begin{array}{l}\text { Chip Compo- } \\
\text { nent Size }\end{array}$ & 2512 & 1206 & 0805 & 0603 & 0402 & 0201 \\
\hline Lead-free & $187-$ & $189-$ & $188-$ & $191-$ & $198-$ & $195-$ \\
$(100 \% \mathrm{Sn})$ & $190^{\circ} \mathrm{C}$ & $192^{\circ} \mathrm{C}$ & $191^{\circ} \mathrm{C}$ & $196^{\circ} \mathrm{C}$ & $206^{\circ} \mathrm{C}$ & $202^{\circ} \mathrm{C}$ \\
$\mathrm{SnPb}$ & $186-$ & $187-$ & $187-$ & $189-$ & $195-$ & $192-$ \\
$(90 \mathrm{Sn} 10 \mathrm{~Pb})$ & $189^{\circ} \mathrm{C}$ & $190^{\circ} \mathrm{C}$ & $189^{\circ} \mathrm{C}$ & $193^{\circ} \mathrm{C}$ & $200^{\circ} \mathrm{C}$ & $197^{\circ} \mathrm{C}$ \\
\hline
\end{tabular}

(7.5 micron) and maximum (15 micron) coating thickness mentioned. It shows that there is no significant increase in mixed composition liquidus temperature from $90 \mathrm{Sn} 10 \mathrm{~Pb}$ to a lead-free pure tin termination. Another point to make is that the final alloy composition for both $\mathrm{SnPb}$ and leadfree components are similar, which is close to $\operatorname{Sn} 37 \mathrm{~Pb}$. The reason is that the coating thickness on a chip component is considerably thinner than that for a BGA/CSP component so it does not significantly affect the mixed solder joint alloy composition.

\subsection{Calculation of the Solder Joint Mixed Composition Liquidus Temperature for Lead-Frame Components}

The typical surface finish for $\mathrm{SnPb}$ lead-frame components is $90 \mathrm{Sn} 10 \mathrm{~Pb}$ with a liquidus temperature of $219^{\circ} \mathrm{C}$. There are several common surface finishes for lead-free leadframe components, for example, $100 \% \mathrm{Sn}$, Sn3.5Ag, Sn1.0Cu, Sn2-4\% wt. Bi, NiPdAu and NiAu. Different surface finishes have their own advantages and disadvantages. In this chapter, the liquidus temperature calculation is limited to the most common lead-frame surface finish, $100 \% \mathrm{Sn}$.

The typical plating thickness for leadframe components of $100 \%$ Sn (leadfree) or $90 \% \mathrm{Sn} 10 \% \mathrm{~Pb}(\mathrm{SnPb})$ is 7.5 to 15 micron. Given a leadframe component dimensions $[27,28]$, the solder volume in the leadframe component can be calculated. Knowing the component pitch and its appropriate stencil aperture openings and paste transfer ratios, the solder paste volume can be calculated.

Table 7.7 summarizes the calculated minimum and maximum liquidus temperature of mixed component joint compositions with $\mathrm{Sn} 37 \mathrm{~Pb}$ paste based on the minimum ( 7.5 micron) and maximum ( 15 micron) coating thickness mentioned for leadframe components. It shows that there is no significant increase in the mixed joint composition liquidus temperature from $90 \mathrm{Sn} 10 \mathrm{~Pb}$ termination to the lead-free pure tin termination similar to the case of the chip component. Again the final alloy composition for both $\mathrm{SnPb}$ and lead-free pure tin components with $\mathrm{SnPb}$ paste are similar, which is close to the composition of $\mathrm{Sn} 37 \mathrm{~Pb}$ solder. 
Table 7. Calculated Final Liquidus Temperature of Leadframe Component Solder Joint

\begin{tabular}{llllll}
\hline $\begin{array}{l}\text { Component } \\
\text { Lead-frame } \\
\text { Pitch (mm) }\end{array}$ & 1.0 & 0.8 & 0.65 & 0.5 & 0.4 \\
\hline Lead-free & $191-$ & $188-$ & $187-$ & $187-$ & $188-$ \\
$(100 \% \mathrm{Sn})$ & $197^{\circ} \mathrm{C}$ & $192^{\circ} \mathrm{C}$ & $190^{\circ} \mathrm{C}$ & $189^{\circ} \mathrm{C}$ & $196^{\circ} \mathrm{C}$ \\
$\mathrm{SnPb}$ & $190-$ & $187-$ & $186-$ & $186-$ & $187-$ \\
$(90 \mathrm{Sn} 10 \mathrm{~Pb})$ & $194^{\circ} \mathrm{C}$ & $190^{\circ} \mathrm{C}$ & $189^{\circ} \mathrm{C}$ & $188^{\circ} \mathrm{C}$ & $189^{\circ} \mathrm{C}$ \\
\hline
\end{tabular}

\subsection{Backward Compatible Solder Joint Reliability of Chip and Lead-frame Components}

The reliability of chip and lead-frame component solder joints in backward compatibility assemblies is not expected to be significantly different from the $\mathrm{SnPb}$ control assemblies. Since the volume of $\mathrm{SnPb}$ solder paste is significantly greater than that of the solder in surface finish of the chip or leadframe components, the final alloy composition in backward compatibility is similar to $\mathrm{Sn} 37 \mathrm{~Pb}$ solder. Thus the liquidus temperature and the reflow profile needed for the final mixed compositions are similar to the eutectic $\mathrm{SnPb}$ solder. There are many years of historical data showing that lead-free chip and lead-frame components in backward compatibility assemblies are reliable. Table 7.8 lists the reliability data of the $2.36 \mathrm{~mm}$ (93 mil) Solectron lead-free surface mount test board after ATC from 0 to $100^{\circ} \mathrm{C}$ for 6,013 cycles. It shows that the reliability of backward compatibility assemblies is comparable to that of $\mathrm{SnPb}$ control assemblies.

Table 8. Reliability Data of Lead-free Pure Sn Leadframe Coatings with $\mathrm{SnPb}$ Paste

\begin{tabular}{llllll}
\hline & $\begin{array}{l}\text { Reflow peak } \\
\text { temperature }\end{array}$ & $\begin{array}{l}\text { Number of samples } \\
\text { failed over number of } \\
\text { samples tested }\end{array}$ & $\begin{array}{l}\text { First failure occurred } \\
\text { (cycles) }\end{array}$ & \\
\cline { 3 - 6 } & & Sn10Pb & $\begin{array}{l}\text { Leadfree } \\
\text { pure Sn }\end{array}$ & Sn10Pb & $\begin{array}{l}\text { Leadfree } \\
\text { pure Sn }\end{array}$ \\
\hline $\begin{array}{l}\text { 28mm QFP256 } \\
\text { 0.4mm pitch }\end{array}$ & $205-215^{\circ} \mathrm{C}$ & $2 / 32$ & $2 / 16$ & 1,022 & 2,213 \\
$\begin{array}{l}\text { SOIC20 } \\
\begin{array}{l}1.27 \mathrm{~mm} \text { pitch } \\
\text { PLCC20 }\end{array}\end{array}$ & $205-215^{\circ} \mathrm{C}$ & $0 / 32$ & $0 / 16$ & - & - \\
$\begin{array}{l}1.27 \mathrm{~mm} \text { pitch } \\
7 \mathrm{~mm} \text { MLF }\end{array}$ & $205-215^{\circ} \mathrm{C}$ & $1 / 32$ & $2 / 16$ & 3,595 & 1,305 \\
$0.5 \mathrm{~mm}$ pitch & $205-215^{\circ} \mathrm{C}$ & $10 / 48$ & $6 / 24$ & 603 & 4,070 \\
\hline
\end{tabular}


In Japan, OEMs have successfully used lead-free SnBi component coatings for lead-free product. The question that has created concern is the use of lead-free $\mathrm{SnBi}$ component coatings with $\mathrm{SnPb}$ soldering materials due to the potential for the formation of low melting point phases. Work has been done by NIST (National Institute of Science and Technology) to understand the $\mathrm{SnBiPb}$ phase diagram [29]. The ternary eutectic composition is approximately $51.5 \mathrm{Bi} 15.5 \mathrm{Sn} 33 \mathrm{~Pb}$ with a melting temperature of $96^{\circ} \mathrm{C}$. Considering a thickness of $0.076 \mathrm{~mm}(3 \mathrm{mil})$ reflowed $63 \mathrm{Sn} 37 \mathrm{~Pb}$ solder joint and a 97Sn3Bi component coating with a coating thickness of 10 micron, the final composition of the joint is around $62.7 \mathrm{Sn} 37 \mathrm{~Pb} 0.3 \mathrm{Bi}$ $(<1 \mathrm{wt} \%$ Bismuth). Based on calculations by NIST the solidus temperature of $62.7 \mathrm{Sn} 37 \mathrm{~Pb} 0.3 \mathrm{Bi}$ is $174^{\circ} \mathrm{C}$ so the $96^{\circ} \mathrm{C}$ ternary eutectic would not form. Calculations have also been done for different $\mathrm{SnPbBi}$ compositions namely $\mathrm{Sn} 37 \mathrm{~Pb} 1 \mathrm{Bi}$ with a solidus temperature of $159^{\circ} \mathrm{C}$ and $\mathrm{Sn} 37 \mathrm{~Pb} 3 \mathrm{Bi}$ with a solidus temperature $119^{\circ} \mathrm{C}$.

The JEDEC/IPC JP002 document [30] indicates that the ternary eutectic phase will not form using Sn1-4wt\%Bi coatings with $\mathrm{Sn} 37 \mathrm{~Pb}$ solder. For most components $\mathrm{SnBi}$ plating is acceptable for use with $\mathrm{SnPb}$ solder. But there may be a risk of excessive intermetallic growth if the storage product temperature exceeds $135^{\circ} \mathrm{C}$. Excessive IMC was observed in ageing experiments with $\mathrm{SnAgCu}$ soldered $\mathrm{SnBi}$ coated surface mount components [31]. Additional reliability testing is needed to validate its use at elevated storage temperatures.

For tin-lead wave soldering, there are still potential restrictions on the use of $\mathrm{SnBi}$ components because the bismuth can leach into a tin-lead wave solder pot and bismuth could accumulate over time in the solder pot, which can lead to a lowering of the melting temperature of the pot and potential reliability issues such as fillet lifting.

\section{Forward Compatibility}

Only a few studies have been published on the reliability of forward compatibility assemblies, or lead-free solder paste $(\mathrm{SnAgCu})$ assembled with tin-lead BGA/CSP and lead-frame and chip components. Though more voids were observed in forward compatibility assemblies for BGAs/CSPs [1], the reliability of forward compatibility assemblies is equivalent or better than the reliability of the $\mathrm{SnPb}$ balled BGAs with $\mathrm{SnPb}$ solder paste $[2,25,32]$.

Nurmi and Ristolainen reported that forward compatibility assemblies did not show any serious reliability risks and can withstand temperature 
cycling stress better than $\mathrm{SnAgCu}$ control assemblies [25]. Experimental studies from the iNEMI lead-free assembly project found no ATC reliability problems in forward compatibility assemblies as well as shown in Table 7.9 [2]. This included lead-free $\mathrm{SnAgCu}$ paste with tin-lead CSP169, CSP208, PBGA256, CBGA256 and 2512 chip resistors. Lau et al. concluded that the quality of the $\mathrm{SnPb}$ balled FLEXBGA solder joints with lead-free solder paste on Ni-Au PCB is better than that with $\mathrm{SnPb}$ solder paste on an OSP PCB with 99 percent confidence level [32]. Note that all studies in forward compatibility assembly used $\mathrm{SnAgCu}$ reflow profiles.

However, Seelig et al. found that a lead-free $\mathrm{SnAgCu}$ soldered joint with a tin-lead coated leadframe component caused a concentration of lead at the joint/board surface interface which was the last area of the solder joint to solidify [33]. The $\mathrm{SnPbAg}$ with a melting temperature of $179^{\circ} \mathrm{C}$ could be present in this area. The resulting solder joint was found to have a weak interface at this point.

For tin-lead coated through-hole components or tin-lead HASL coated boards waved with lead-free solder, the risk of lead contamination of a leadfree wave solder pot $(>0.1 \mathrm{wt} \%$ lead which is the European Union ROHS limit) would mean that this specific mixing should not be attempted. Fillet lifting may also occur in the wave soldered joint.

There are issues as to whether the tin-lead component or other components on the board or the board itself are rated to the higher lead-free soldering temperatures. Based on our knowledge, this has not been discussed in published literature. In addition, the resulting solder joint would not be compliant to legislative direction.

Table 7.9. Relative ATC Performance [2]

\begin{tabular}{lllllll}
\hline Component (ImAg board finish & \multicolumn{3}{c}{$-40^{\circ} \mathrm{C}$ to $125^{\circ} \mathrm{C}$} & \multicolumn{3}{c}{$0^{\circ} \mathrm{C}$ to $100^{\circ} \mathrm{C}$} \\
\cline { 2 - 7 } unless indicated) & $\mathrm{Pb}$ & Mixed & $\mathrm{LF}$ & $\mathrm{Pb}$ & Mixed $\mathrm{LF}$ \\
\hline 48 TSOP & 0 & - & 0 & & \\
48 TSOP, NiAu boards & 0 & + & + & & \\
R2512 resistor & 0 & 0 & 0 & & & + \\
R2512, NiAu boards & 0 & & & & & + \\
169CSP & 0 & + & + & 0 & 0 & + \\
208CSP & 0 & 0 & + & 0 & + & + \\
208CSP, JEITA alloy & & & 0 & & & + \\
(Sn3Ag0.5Cu) & & & & & & + \\
256PBGA & 0 & 0 & 0 & 0 & 0 & 0 \\
256CBGA & & & & 0 & - & + \\
\hline
\end{tabular}

Note: $0=$ equivalent, $+=$ superior, $-=$ inferior 


\section{Press Fit Connector Interconnections}

\subsection{Introduction for Press-Fit Connectors}

The European Union RoHS Directive covers various aspects of electronics manufacturing including press-fit interconnections. In spite of the current exemption for lead used on compliant pin connector systems, the transition to lead-free press-fit interconnect components is inevitable and in progress. OEMs, EMSs, and connector suppliers are working together to make the connectors used in electronics products RoHS compliant. In the transition period, lead-free press-fit connectors are required to have backward and forward compatibility meaning they can be used in both lead-free and tinlead assembly processes on any surface finish selected.

\subsection{Current Status of Lead-Free Press-Fit Connectors}

In the area of press-fit interconnections, lead-free impacts are seen in the changes of press-fit connector compliant pin plating, PCB laminate material, and board surface finish. For press-fit connector compliant pins, the main plating includes matte $\mathrm{Sn}$ and electroplated $\mathrm{Au}$ (over nickel). For the PCB, the major board surface finishes include Immersion Sn, ENIG (NiAu), Immersion $\mathrm{Ag}$, and OSP. The combination of the compliant pin plating with the board surface finish will generate various press-fit insertion force results as opposed to tin-lead connector compliant pin plating with the board surface finish. To date, no comprehensive studies and industry-accepted conclusions are available that satisfy all design and assembly conditions. Nevertheless, there are a few mixed observations obtained from production experience or derived from OEM/EMS/connector supplier studies:

- Lead-free compliant pins experienced increased insertion forces due to interactions among various pin design attributes (eye-of-needle and other custom-made compliant sections), compliant pin plating type, and board surface finish type, as compared to its tin-lead coated counterpart compliant pins given the same PCB Plated Through Hole (PTH) size. Failures such as bent pins and PTH damage have been seen when pressing in lead-free coated compliant pins into the board [34].

- Depending on the compliant pin design, PCB surface finish type, the pin-to-hole area ratio, the lead-free coated compliant pin can have as hihg as a $15 \%$ average increase in insertion force over tin-lead coated compliant pin [35].

- According to a study [36], the NiAu board surface finish caused higher insertion/retention force as opposed to other board surface 
finishes tested. This study recommended immersion Ag as a suitable choice among RoHS compliant PCB finishes in terms of relatively lower insertion/retention force with lead-free press-fit connectors.

- Another study showed that immersion Sn caused highest insertion forces with the lead-free press-fit connector, among six board surface finishes tested [37].

- The actual PCB laminate material used (such as Phenolic non-dicy laminate) that is rated for lead-free reflow conditions might contribute partially to the increase of insertion forces with lead-free press-fit connectors as it may be harder and less forgiving than the standard laminate material (dicy laminate) used for typical tin-lead soldering. This phenomenon is yet to be fully understood and studied.

With the increase of compliant pin insertion forces, changes in design and assembly processes have to take place accordingly to ensure that the yield and performance of lead-free press-fit interconnection are not compromised. Long-term solutions for the lead-free press-fit connector supplier could be 1) to change the compliant pin geometry design to be more suitable for leadfree insertion assembly, or 2) to study the lead-free compliant connectors' press-fit behavior on various lead-free PCB surface finishes and update their connector specifications accordingly. Before this can materialize, shortterm solutions include 1) reducing the connector pressing speed into the board, 2) using lubricant to reduce insertion force, or 3) changing PCB PTH drill and/or finished hole size.

\subsection{Lead-Free Press-Fit Connector Summary}

Due to the press-fit compliant pin plating changing from $\mathrm{SnPb}$ to a lead-free finish, the press/insertion process needs to be re-characterized. Currently there are only limited studies done by OEM/EMS/connector suppliers in this regard. No conclusion can be drawn yet in terms of the selection of the best PCB surface finish, PCB laminate material, and compliant pin plating. It is recommended that EMS providers and their OEM customers, as well as connector suppliers work together to make the lead-free press-fit interconnection transition smooth without compromising quality and reliability.

\section{Summary}

In this chapter, backward compatibility and forward compatibility have been reviewed with emphasis on the reliability of BGA/CSP backward compatibility assemblies. It is evident that the reliability of solder joint 
interconnections in backward compatibility assemblies degrades significantly if $\mathrm{SnAgCu}$ solder spheres are only partly melted in backward compatibility. If complete mixing is achieved in backward compatibility assemblies, there are conflicting experimental results on the reliability of BGA/CSP backward compatibility. Data show that the backward compatibility assemblies of chip components and leadframe components are reliable in terms of solder joint integrity.

The estimation of the liquidus temperature of mixed composition in backward compatibility has been presented for BGA/CSP, lead-frame and chip components. The estimation for BGA/CSP components could be used to guide the development of a reflow profile, but it should be noted that the estimation is an approximation and further experimental study is needed to validate the accuracy of the method.

The majority of forward compatibility studies show little or no issues but excessive voiding of tin-lead BGA/CSP components is a concern. The effect of $\mathrm{Pb}$ content in mixed assemblies (forward compatibility and backward compatibility) is still questionable.

Both the backward and forward compatibility situations should be considered as transitional processes only with a full movement to lead-free paste with lead-free components being the general goal to avoid any reliability issues associated with the two transition assembly situations.

\section{Acknowledgements}

The first author, J. Pan would like to express his gratitude to the Solectron Corporation, Milpitas, CA, for technical and financial support; to Kim Hyland, Dennis Willie, without whom this work would not have been possible. He would also like to thank Dr. Ursula Kattner and Dr. Carol Handwerker for their valuable technical discussions.

\section{References}

1. Smetana J, Horsley R, Lau J, Snowdon K, Shangguan D, Gleason J, Memis I, Love D, Dauksher W, Sullivan B (2004) Design, materials and process for lead-free assembly of high-density packages. Soldering \& Surface Mount Technology, 16 (1): 53-62.

2. Handwerker C, Bath J, Benedetto E, Bradley E, Gedney R, Siewert T, Snugovsky P, Sohn J (2003) NEMI Lead-free Assembly Project: Comparison Between PbSn and SnAgCu Reliability and Microstructures. In: Proceedings of the SMTA International Conference. 
3. Lau JH, Liu K (2004) Global trends of lead-free soldering. Advanced Packaging Jan. 2004.

4. Grossmann G, Tharian J, Jud P, Sennhauser U (2005) Microstructural investigation of lead-free BGAs soldered with tin-lead solder. Soldering \& Surface Mount Technology 17 (2): 10-21.

5. Bath J, Sethuraman S, Zhou X, Willie D, Hyland K, Newman K, Hu L, Love D, Reynolds H, Kochi K, Chiang D, Chin V, Teng S, Ahmed M, Henshall G, Schroeder V, Nguyen Q, Maheswari A, Lee MJ, Clech J-P, Cannis J, Lau J, Gibson C (2005) Reliability Evaluation of Lead-free SnAgCu PBGA676 Components using Tin-Lead and Lead-free $\mathrm{SnAgCu}$ solder paste. In: Proceedings of 2005 SMTA International, Chicago, IL, 891-901.

6. Zbrzezny AR, Snugovsky P, Lindsay T, Lau R (2005) Reliability Investigation of Sn-Ag-Cu BGA Memory Modules Assembled with Sn-Pb Eutectic Paste Using Different Reflow Profiles. In: International Conference on Lead-free Soldering, CMAP, Toronto, Ontario, Canada, May 24-26, 2005.

7. Hua F, Aspandiar R, Anderson C, Clemons G, Chung C, Faizul M (2003a) Solder Joint Reliability Assessment of Sn-Ag-Cu BGA Components Attached with Eutectic Pb-Sn Solder. In: SMTA International 2005, Chicago, IL, pp. 246-252.

8. Nandagopal B, Chiang D, Teng S, Thune P, Anderson L, Jay R, Bath J (2005) Study on Assembly, Rework, Microstructures and Mechanical Strength of Backward Compatible Assembly. In: Proceedings of 2005 SMTA International, Chicago, IL, pp. 861-870.

9. Nandagopal B, Mei Z, Teng S (2006) Microstructure and Thermal Fatigue Life of BGAs with Eutectic Sn-Ag-Cu Balls Assembled at $210^{\circ} \mathrm{C}$ with Eutectic $\mathrm{Sn}-\mathrm{Pb}$ Solder Paste. In: Proceedings of 2006 IEEE Electronic Components and Technology Conference, San Diego, CA, pp. 875-883.

10. Handwerker, C. (2005) Transitioning to Lead-free Assemblies, Printed Circuit Design and Manufacture, March Issue, pp. 17-23.

11. Snugovsky P, Zbrzezny AR, Kelly M, Romansky M (2005) Theory and Practice of Lead-free BGA Assembly using $\mathrm{Sn}-\mathrm{Pb}$ Solder. In: International Conference on Lead-free Soldering, CMAP, Toronto, Ontario, Canada, May 24-26, 2005.

12. Hillman D, Wells M, Cho K (2005) The Impact of Reflowing a Pb free Solder Alloy Using a Tin/Lead Solder Alloy Reflow Profile on Solder Joint Integrity. In: International Conference on Lead-free Soldering, CMAP, Toronto, Ontario, Canada, May 24-26, 2005.

13. Gregorich T, Holmes P (2003) Low-Temperature, High Reliability Assembly of Lead-free CSPS. In: IPC/JEDEC 4th International Conference on Lead-free Electronic Components and Assemblies, Frankfurt, Germany, 2003.

14. Hua F, Aspandiar R, Rothman T, Anderson C, Clemons G, Klier M (2003b) Solder Joint Reliability of Sn-Ag-Cu BGA Components Attached with Eutectic Pb-Sn Solder Pate. Journal of Surface Mount Technology 16 (1): 34-42.

15. Sun F (2005) Solder Joint Reliability of Sn-Ag-Cu BGA and Sn-Pb Solder Paste. In: Proceedings of the $6^{\text {th }}$ IEEE International Conference on Electronic Packaging Technology, Shenzhen, China. 
16. Theuss H, Kilger T, Ort T (2003) Solder Joint Reliability of Lead-Free Solder Balls Assembled with SnPb Solder Paste. In: Proceedings of 2003 IEEE Electronic Components and Technology Conference, New Orleans, LA, pp. 331-337.

17. iNEMI (2006) Backward Compatibility Project Presentation. In: IPC Printed Circuits Expo, APEX and the Designers Summit, NEMI forum, Anaheim, CA, Feb. 8-10.

18. Pan J (2006) Estimation of Liquidus Temperature when $\mathrm{SnAgCu} B G A / C S P$ Components are Soldered with $\mathrm{SnPb}$ Paste. In: Proceedings of the $7^{\text {th }}$ International Conference on Electronics Packaging Technology, Shanghai, China.

19. Pan J, Bath J (2006) Lead Free Soldering Backward Compatibility. In: IPC/JEDEC 12th International Conference on Lead Free Electronic Components and Assemblies, Santa Clara, CA, March 7-9, 2006.

20. Siewert T, Liu S, Smith DR, Madeni JC (2002) Database for solder properties with emphasis on new lead-free solders. NIST \& Colorado School of Mines, Release 4.0, Feb. 2002, http://www.boulder.nist.gov/div853/lead free/solders.html

21. Kattner UR, Handwerker C (2001) Calculation of Phase Equilibria in Candidate Solder Alloys. Z. Metallkd. 92: 1-10.

22. Kattner UR, Handwerker C (2005) personal communication though emails.

23. Zhu Q, Sheng M, Luo L (2000) The effect of Pb contamination on the microstructure and mechanical properties of $\mathrm{SnAg} / \mathrm{Cu}$ and $\mathrm{SnSb} / \mathrm{Cu}$ solder joints in SMT. Soldering and Surface Mount Technology, 12 (3): 19-23.

24. Zeng X (2005) Thermodynamic analysis of influence of $\mathrm{Pb}$ contamination on $\mathrm{Pb}$-free solder joint reliability. Journal of Alloys and Compounds, 348: 184-188.

25. Nurmi ST, Ristolainen (2002) Reliability of Tin-lead Balled BGAs Soldered with Lead-free Solder Paste. Soldering and Surface Mount Technology, 14 (2): 35-39.

26. Hunt $C$ and Wickham M (2006) Impact of Lead Contamination on Reliability of Lead Free Alloys. In: Proceedings of IPC Printed Circuits Expo, APEX and the Designers Summit, Anaheim, CA, Feb. 8-10, S39-01-1 -11.

27. Practical Components webpage at http://www.practicalcomponents.com/

28. Topline webpage at http://www.topline.tv/

29. Moon K, Boettinger WJ, Kattner UR, Handwerker CA, and Lee D (2001) The Effect of $\mathrm{Pb}$ contamination on the Solidification Behavior of Sn-Bi Solders. Journal of Electronic Materials, 30 (1), 45-52.

30. JEDEC/IPC (2006) Current Tin Whiskers Theory and Mitigation Practices Guideline. March.

31. Henshall G, Roubaud P and Chew G (2002) Impact of Component Terminal Finish on the Reliability of Pb-free Solder Joints. In: Proceedings of the SMTA International Conference.

32. Lau J, Hoo N, Horsley R, Smetana J, Shangguan D, Dauksher W, Love D, Menis I, Sullivan B (2004) Reliability Testing and Data Analysis of Lead-free Solder Joints for High-density Packages. Soldering and Surface Mount Technology, 16 (2): 46-68.

33. Seelig K and Suraski D (2001) Advances Issues in Assembly: Part 1 Lead Contamination in Lead-free Assembly. In: SMT Magazine, October.

34. Solectron internal data. 
35. Verhelst $\mathrm{E}$ and Ocket $\mathrm{T}$ (2002) Lead-free manufacturing: Effects on press-fit connections. White Paper, Tyco Electronics.

36. Pal I, Smolentseva E (2006) An Experimental Study of Press-fit Interconnection on Lead Free Plating Finishes. In: Proceedings of SMTAI, Chicago, IL.

37. Chou GJS and Hilty RD (2003) Effects of Lead-free Surface Finishes on Press-fit Connections. In: Proceedings of the IPC Annual Meeting, Minneapolis, MN. 